Revista Signos 2008, 41(67) 299-328

\title{
Interpretaciones de la atenuación en artículos de revisión de Odontología ${ }^{1}$
}

\author{
Oscar Morales \\ Daniel Cassany \\ Universitat Pompeu Fabra \\ España
}

\begin{abstract}
Resumen: Este trabajo analiza cómo interpretan la atenuación 25 estudiantes universitarios venezolanos de Odontología, de nuevo ingreso, al responder a dos cuestionarios luego de leer un artículo de revisión. En el primero, con preguntas abiertas, debían interpretar algunas expresiones atenuadas preseleccionadas; en el segundo, debían elegir entre varias interpretaciones cerradas de los mismos fragmentos. Clasificamos sus respuestas en las siguientes categorías: reconocimiento, supresión y aumento de la atenuación, en el primer cuestionario; identificación de aproximadores, escudos, deícticos y construcciones impersonales, en el segundo. En los resultados predomina la identificación de atenuadores asociados a la dimensión semántica: el $30 \%$ reconoció la atenuación tal como fue usada en el original, el $30 \%$ aumentó su valor y el $40 \%$ no la logró identificar. Los estudiantes identificaron con mayor frecuencia los aproximadores, a diferencia de los escudos, las construcciones impersonales y los deícticos temporales. Estos resultados sugieren que es necesario formar a los estudiantes en el uso especializado de las dimensiones pragmática y sociocognitiva de la atenuación, en cursos de lectura y escritura académica. Solo este conocimiento específico permitirá que los estudiantes dominen el discurso científico prototípico de la Odontología.
\end{abstract}

Palabras Clave: Lectura, interpretación, atenuación, artículos de revisión.

Recibido: 21-III-2007 Aceptado: 11-I-2008
Correspondencia: Oscar Morales (oscarula@ula.ve). Tel.: (34-93) 52921412. Fax: 5421617. Departamento de Traducción y Filología, Universitat Pompeu Fabra. Ramblas 30-32, 08002, Barcelona, España. 


\title{
Hedging interpretations in Dental review articles
}

\begin{abstract}
This paper analyzes how 25 Venezuelan Dental university fresh men students interpret hedging when answering two questionnaires after having read a Dental review article. In the first one, they should interpret hedged expressions; in the second one, they should choose among several closed interpretations of some hedged expressions. We organized the results in the following categories: From the first questionnaire, identification, suppression, and fertilization of hedges; from the second one, identification of approximators, shields, deictics and impersonal constructions. We found that the identification of hedges associated with the semantic dimension predominated. 30\% recognized hedging as it was used in the original text, 30\% fertilized hedging and $40 \%$ did not identify hedging devices at all. The students identified approximators more frequently, but they fail in identifying hedging expressed in shields, impersonal constructions or in temporary deictics. Since these students could not interpret the pragmatic and socio-cognitive dimensions of discourse associated with hedging, it is necessary to teach these devices in the academic reading and writing courses. The capacity to interpret and use hedging strategies will allow the students be more competent in using prototypical Dental scientific discourse.
\end{abstract}

Key Words: Reading, interpretation, hedging, review articles.

\section{INTRODUCCIÓN}

Cada comunidad científica construye sus propias formas discursivas. La comunicación no se limita a la transmisión de saberes disciplinares; también pone en juego un conjunto de significados lingüísticos, pragmáticos, retóricos, contextuales y socio-cognitivos que hay que dominar para ser competente en la disciplina y, en consecuencia, para formar parte de la comunidad correspondiente (Candlin \& Hyland, 1999; Hyland, 2000b). Cassany (2006b: 12) lo formula así:

"(...) cada disciplina genera sus propios modos de comunicación escrita. Leemos y escribimos de manera diferente en el Derecho y en la Odontología, pero también en la Historia o en el periodismo. Leer y escribir no es solo un instrumento para comunicar conocimiento especializado. También es una manera de construir el conocimiento, de elaborarlo. Y también es una herramienta para armar una identidad personal, para presentar el perfil profesional o académico o cívico de una persona (...) y para ganar -jo perder!- estatus y poder en la comunidad. Si leemos y escribimos bien, construimos una identidad más definida y ganamos estatus y poder (...) o viceversa".

Junto con los contenidos conceptuales, los estudiantes universitarios deben adquirir la "literacidad especializada", o sea, este conjunto de rasgos discursivos que se manifiestan en la lectura y la escritura de los discursos propios. Siguiendo esta tesis, Parodi $(2004,2006)$ propone que la enseñanza y el aprendizaje de esta literacidad se avance a los niveles medios técnicos profesionales, sin esperar a la universidad. 
Myers (1989), Salager-Meyer (1994), Hyland (1994) y Vold (2006) coinciden en señalar que los estudiantes deben familiarizarse con el uso de las estrategias retóricas discursivas empleadas en su disciplina, para formarse como lectores y escritores efectivos de textos científicos e incorporarse a su comunidad. Por lo tanto, los atenuadores deben ser enseñados de acuerdo con las convenciones de cada comunidad (Swales, 1990; Hyland, 1998b; Oliver, 2004). Hyland (2001: 209) considera que:

"(...) publishing in academic journals demands that the author displays some degree of disciplinarity, that he or she demonstrates a familiarity with the rhetorical conventions and social understandings of the community, and observes suitable patterns of social and rhetorical interactions".

Esto supone, entre otras cosas, el desarrollo de una competencia para leer críticamente (Cassany, 2006a): poder comprender e interpretar no solo lo que está explícito en las líneas (dimensión semántica) o lo inferido entre líneas (inferencial), sino también lo implicado: las intenciones, posturas (pragmáticas), el nivel de certidumbre y compromiso del autor (retórica), su estatus y rol en la comunidad (social), su concepción de la ciencia (ideología, valores) y los prejuicios y estereotipos que intenta transmitir (socio-cognitivos).

El desarrollo de esta capacidad se puede lograr leyendo y escribiendo discursos científicos (investigaciones, revisiones, divulgaciones), analizándolos y discutiendo sobre ellos. Jackson, Meyer y Parkinson (2006) consideran que esta práctica, entre otras, permite desarrollar conocimientos disciplinares, retóricos, pragmáticos y discursivos. A través de la lectura de estos géneros discursivos, el estudiantado puede, en palabras de estos autores:

"(...) sort out new knowledge from old; attribute credit to researchers; assess the certainty of statements; infer cohesive links between knowledge; and trace the relation to other texts" (Jackson et al. 2006: 4).

Muchos autores consideran que sería conveniente incluir la atenuación como parte de la enseñanza de la lectura y escritura del discurso científico en la universidad (Markkanen \& Schröder, 1989; Myers, 1992; Hyland, 1994; Salager-Meyer, 1994; Scout, 1997; Fortanet, Palmer \& Postiguillo, 2001). Fortanet et al. (2001: 252) resaltan la importancia de los atenuadores ya que "(...) students are able to better understand scientific texts if they can identify hedging devices used". Según Hyland (2000a) y Réfega (2001), los estudiantes deben tomar conciencia de los atenuadores y de su impacto semántico y pragmático, además de desarrollar la habilidad para reconocerlos e interpretarlos cuando leen. Esto es crucial para hacerse competente en cualquier disciplina.

La revisión de la literatura muestra que no hay estudios sobre la lectura de textos científicos 
en el ámbito de la Odontología. Como una primera aproximación, esta investigación se propone conocer cómo interpretan los estudiantes universitarios de nuevo ingreso las estrategias de atenuación utilizadas en un artículo de revisión (AR, a partir de ahora) prototípico de Odontología, a partir de las respuestas que dieron a dos cuestionarios de comprensión.

Si identificamos el conocimiento previo que tienen los preuniversitarios sobre los géneros específicos de su campo, podremos diseñar programas y recursos didácticos para desarrollar con más eficacia la capacidad de interpretar y producir los géneros discursivos propios de cada ámbito, de forma similar a cómo lo hacen los miembros establecidos de la comunidad. Eso incrementaría el desarrollo académico de los estudiantes y aceleraría su ingreso a la comunidad científica.

\section{Marco Teórico}

Resumimos la investigación previa sobre a) el artículo de revisión en Odontología, b) la atenuación, c) la lectura crítica y d) la lectura de la atenuación.

\subsection{El artículo de revisión en Odontología}

El AR es "(...) un estudio pormenorizado, selectivo y crítico, que integra la información esencial en una perspectiva unitaria de conjunto" (Pulido, 1989: 745). Consiste en la revisión y análisis de un determinado tema desde dos perspectivas: la experiencia del autor como experto y la síntesis de la bibliografía publicada sobre el particular (Pulido, 1989; Alcaraz \& Salager-Meyer, 2002). El AR examina y resume los estudios primarios más relevantes y de más alto nivel de confiabilidad (Oxman \& Guyatt, 1994) y "(...) su finalidad es examinar la bibliografía publicada anteriormente y situarla en cierta perspectiva" (Day, 1990: 120).

El AR es un género discursivo ampliamente leído y escrito en el área biomédica, tanto en el ámbito académico e investigador como profesional (Webber, 1994). En Odontología, al igual que en Medicina, el AR es insustituible para los clínicos que desean mantenerse actualizados y aplicar los avances científicos en su práctica clínica, y para los científicos que no pueden acceder directamente a todas las fuentes originales (Morales, González \& Tona, 2006). También es un recurso útil para los lectores de áreas afines o interdisciplinarias, que no conocen el campo específico. Además de sintetizar la información, el AR selecciona los originales más confiables y valiosos, entre la gran cantidad y diversidad de materiales difundidos (Morales et al., 2006).

Por su función social y propósitos comunicativos, el AR debe leerse de manera crítica tanto en el contenido como en la forma. Se requiere diferenciar lo que está atenuado de lo que no lo está: identificar los niveles de certidumbre, duda, precisión y compromiso (o falta de compromiso y escepticismo) que intenta expresar el autor. Esto es fundamental para decidir, entre otras cosas, si se pone en práctica lo expuesto en el AR. Por ejemplo, con la atenuación se determina si un 
tratamiento es el más adecuado que otro, si la terapia farmacológica es la más pertinente o si las contraindicaciones y efectos son manejables para un determinado paciente (Oxman, 1994). Para una óptima aplicación clínica, el lector debe identificar e interpretar el texto integralmente, incluyendo lo no dicho, los implícitos.

Así mismo, la lectura de AR en el contexto académico odontológico puede tener aplicaciones didácticas. En las facultades de Odontología, se producen monografías y otros textos académicos cuyas características retóricas y textuales son similares a las del AR. Al incluir el estudio del AR en la actividad docente, se podría enseñar al mismo tiempo el contenido de las asignaturas odontológicas clínicas, la lectura y la escritura académica, la investigación y los rasgos discursivos de este género (Morales \& Espinoza, 2001, 2005).

\subsection{La atenuación}

En su trabajo pionero, Lakoff (1972: 195) afirma que los atenuadores son "(...) words or phrases whose job is to make things fuzzier". Prince, Frader y Bosk (1982: 85) discrepan de Lakoff, puesto que consideran que los atenuadores no solo tienen la finalidad de crear falta de claridad; cumplen, en cambio, dos funciones distintas:

"(...) one class of hedges introduces, or is responsible for, fuzziness within the propositional content proper (aproximadores), while the other class of hedges correlates with fuzziness in the relationship between the propositional content and the speaker".

En otras palabras, los atenuadores correlacionan el compromiso del hablante con la verdad de la proposición expresada (escudos).

Myers (1989), Swales (1990), Hyland (1994) y Salager-Meyer (1994) definen los atenuadores como un conjunto de mecanismos estilísticos, retóricos y pragmáticos, altamente persuasivos, convencionales de cada comunidad discursiva. Se emplean en la comunicación científica entre especialistas con un doble propósito: a) desde una dimensión semántica, para suavizar o reducir la fuerza o el nivel de certidumbre de una proposición, para expresar así la tentatividad del saber científico, y b) desde una dimensión retórica y pragmática, para reducir el grado de compromiso del autor con sus afirmaciones, para evitar las amenazas hacia los miembros de la comunidad ya establecidos y, así, evitar los potenciales rechazos y críticas.

\subsubsection{Funciones de los atenuadores}

Algunos investigadores (Myers, 1989; Hyland, 1994, 1998a y 1998b; Salager-Meyer, 1994; Oliver, 2004; Lewin, 2005; Vold, 2006) coinciden en que los atenuadores desarrollan distintas funciones en el escrito científico: 
- Expresar imprecisión (vaguedad), falta de claridad e incertidumbre de la proposición.

- Presentar la verdad como relativa, tentativa y abrir la posibilidad de otras alternativas, explicaciones, resultados, terapias, efectos, etc.

- Proyectar modestia, humildad, precaución, duda personal, amabilidad y falta de compromiso con el contenido expresado.

- Criticar a otros autores con precaución.

- Evitar críticas potenciales de parte de sus pares.

- Distanciarse de lo expresado, eliminando u ocultando el punto de vista personal.

- Mitigar ofensas potenciales a los miembros de la comunidad científica.

- Negociar la incorporación a la comunidad científica al usar mecanismos (atenuadores) que le son propios.

- Mostrar honestidad al expresar las limitaciones del propio trabajo.

- Involucrar a los lectores para que acepten las afirmaciones presentadas en el texto.

\subsubsection{Clasificación}

Existen varias aproximaciones clasificatorias de los atenuadores empleados en la prosa y el habla que se complementan entre sí. Presentamos solo las más representativas.

Prince et al. (1982) estudiaron el discurso oral entre médicos y distinguen dos grupos de atenuadores:

a. Aproximadores. Afectan al contenido proposicional, su verosimilitud y su certidumbre, pero no al compromiso del hablante. Se caracterizan por presentar los datos sin precisión. Entre estos cabe mencionar: adverbios de cantidad, de grado, de frecuencia y de tiempo. Ejemplos: aproximadamente, alrededor, más o menos, de alguna forma, cerca de, ocasionalmente. Pueden ser redondeadores o adaptadores.

b. Escudos. Afectan al compromiso del hablante con lo expresado y con la audiencia (dimensión retórico-pragmática). Intentan disminuir o mitigar la verdad de la proposición expresada y proyectar una actitud modesta y humilde en la comunidad. Son verbos modales, verbos no objetivos (epistémicos) o adverbios y adjetivos de posibilidad y probabilidad, como poder, podría, parecer, sugerir, posible, probable. Se distinguen los escudos de posibilidad (para expresar duda, incertidumbre) y los de atribución (para atribuir creencias a otros, de modo que el compromiso personal del interlocutor se infiere indirectamente).

Salager-Meyer (1994), por su parte, estudió cinco tipos en artículos de investigación, de revisión y casos clínicos médicos: escudos, aproximadores, dudas personales e involucramientos 
del autor, intensificadores cargados de emotividad y atenuadores compuestos. Posteriormente, Salager-Meyer y Defives (1998) incorporaron la voz pasiva como tipo de atenuante en el discurso médico.

También Luukka y Markkanen (1997) y Oliver (2004) incluyeron las construcciones impersonales como una sub-estrategia de atenuación. Esta última autora los estudió junto con las categorías empleadas por Salager-Meyer (1994).

La impersonalidad se utiliza para expresar falta de compromiso con el contenido, eliminando u ocultando el punto de vista personal, y para mitigar ofensas potenciales a los miembros de la comunidad. Incluye la desagentivación, entendida como la elisión de toda marca del sujeto enunciador o del responsable de la proposición; la nominalización; el plural de la $1^{a}$ persona (referido a un grupo vago, general); las pasivas desagentivadas y el impersonal propiamente dicho (se sabe, se puede, hay, se cree).

Hyland (1998b) clasificó la atenuación en dos grandes grupos, desde una perspectiva pragmática:

a. la atenuación orientada hacia el contenido (de la que derivan dos subtipos: la orientada hacia el escritor y la orientada hacia la precisión);

b. la atenuación orientada hacia el lector.

Fortanet, Palmer y Postiguillo (2001) aplicaron la taxonomía de Salager-Meyer (1994) e incluyeron los paréntesis y las comillas empleadas como atenuadores.

Desde la retórica contrastiva, Vold (2006) analizó un corpus multilingüe de artículos científicos de Medicina y Lingüística y agrupó los atenuadores en dos categorías: atenuadores reales, estrategias utilizadas para expresar incertidumbre o un determinado nivel (semántico) de certeza de la proposición; y atenuadores estratégicos, asociados a la expresión de tentatividad, precaución, amabilidad y humildad del autor (pragmático).

Finalmente, Morales, Cassany y González (2007) consideraron también los deícticos temporales, empleados como estrategia de atenuación, en su estudio de los AR odontológicos. Las expresiones deícticas temporales (hoy en día, hoy día, actualmente, hasta ahora, en la actualidad, hoy, en el día de hoy, entre otros) fijan el alcance de la aseveración a un tiempo determinado, referido al momento de la enunciación, presentando el saber como dinámico, flexible y cuestionable; se ofrece la posibilidad de interpretaciones alternativas en el futuro y se llama a la precaución.

\subsection{La lectura crítica}

Desde 1960, varios teóricos e investigadores han desarrollado modelos y aplicaciones didácticas 
de la lectura, basándose en datos empíricos y partiendo de la idea de que al leer empleamos unos procesos generales independientemente del tipo de texto, idioma, cultura o tema. Sin ser exhaustivos, citamos algunos referentes próximos a este trabajo.

Para las teorías que priorizan el código escrito (perspectiva lingüística), el significado se aloja en el texto. Conciben la lectura como un conjunto de habilidades que pueden ser enseñadas aisladamente, partiendo de lo más sencillo: letras, sonidos y sílabas, luego la palabra, para llegar finalmente a la recuperación del significado, entendido como una construcción única, objetiva, estable (Samuels \& Laberge, 1985; Cassany, 2006a).

Desde la perspectiva psicolingüística, que destaca los componentes cognitivos de la lectura, resaltan autores como Rosenblatt (1985a, 1985b), Goodman (1980a; 1980b; 1994; 2005) y Smith (1990, 1997, 1999). Estos coinciden en definir la lectura como un acto de negociación entre las aportaciones del lector (conocimiento previo, inferencias) y los datos del texto, situados ambos en un contexto determinado. El significado no existe de antemano en el texto o en el lector, sino que surge en el encuentro entre ambos. El lector selecciona algunas pistas pertinentes del texto e información de sus esquemas, para construir el significado, que se aloja en su mente y que varía entre lectores y situaciones, puesto que cada uno introduce matices y variaciones.

Las interpretaciones semióticas de la lectura han sido abundantes. Por razones de espacio, desde esta perspectiva se considerarán solo los aportes de Eco y Greimas. Eco (1981) define la lectura como un proceso en el que el lector, valiéndose de su competencia circunstancial y su competencia enciclopédica, actualiza el contenido del texto, completa los espacios en blanco que encuentra en él. El texto, por lo tanto, es una "máquina perezosa" que exige del lector un arduo trabajo cooperativo para llenar espacios vacíos: lo "no dicho", lo "ya dicho", los elementos no manifiestos en la superficie, en el plano de la expresión. Este proceso de actualización favorece al lector, ya que contribuye con el desarrollo de su competencia.

Por su parte, Greimas (Greimas \& Courtés, 1982; Greimas, 1983) aborda la lectura desde la perspectiva del texto, definido como una realidad significativa, como un todo de significación, del cual parte el lector para reconstruir su significado con la mayor fidelidad semántica posible, tomando como referencia "el significado" del autor. Toma como referencia el concepto "isotopía", que designa la coherencia de un recorrido semántico del texto, de aquello de lo que el texto trata y que permite mantener la cohesión del mismo, para designar el mecanismo que determina los límites de la interpretación.

Finamente, la lectura adopta también una perspectiva sociocultural y crítica. Según Cassany (2003), la posibilidad de que existan varios grados o planos de lectura en un mismo texto ya es muy aceptada. Citando a Gray, Alderson (2000: 7) distingue entre leer "las líneas", leer "entre líneas" y leer "detrás de las líneas", que corresponden a estos tres planos: a) comprender el 
significado literal, b) hacer inferencias, y c) evaluar críticamente lo leído (Cassany, 2003). Para Cassany (2006b) la lectura crítica supone:

- recuperar las connotaciones, los dobles sentidos, la orientación argumentativa que tiene el discurso (incluso el imaginario o las representaciones mentales que subyacen a lo dicho);

- construir una interpretación global y detallada y una valoración personal de la misma;

- identificar las intenciones del autor (sus motivaciones, propósitos, posicionamiento en la comunidad científica);

- tomar conciencia del género textual al que pertenece el discurso, así como de la comunidad discursiva en la que se ha elaborado (interlocutores, conocimiento compartido por ellos, prácticas comunicativas más habituales, etc.); y

- valorar hasta qué punto el texto en cuestión respeta las convenciones establecidas por esta comunidad.

En síntesis, los autores citados coinciden en que la lectura es un proceso activo de construcción del significado, de creación de sentidos para compensar un desequilibrio o para atribuir pertinencia a unos indicios. El texto es considerado como unidad, no necesariamente material, tangible, cuyo sentido debe, de algún modo, ser extraído (lingüístico), construido o reconstruido (psicolingüístico), completado (semiótico) o construido críticamente (crítica).

\subsection{La lectura de la atenuación}

Si bien la atenuación ha sido ampliamente descrita en el discurso científico en varias disciplinas, lenguas y géneros (Varttala, 2001; Oliver, 2004; Mendiluce \& Hernández, 2005), no ocurre lo mismo con la lectura e interpretación que de estos recursos hacen los sujetos. Son escasos los estudios que relacionan el uso lingüístico con la interpretación pragmática (Hyland, 2000a; Lewin, 2005). Pese a esta situación, la atenuación es una estrategia relevante que debe ser considerada en la lectura del discurso científico. Tanto el lector como el escritor son fundamentales para la concreción del significado de la atenuación en un contexto concreto. Markkanen y Schröder (1997: 9) consideran que "(...) a hedge exists when it is mutually recognized by author and reader". Por su parte, Low (1996) estudió la interpretación de los atenuadores e intensificadores en la lectura de cuestionarios; encontró que los estudiantes no prestan atención a los atenuadores al responder a los cuestionarios; no toman conciencia de ellos, puesto que no afectan a la comprensión; no los consideran necesarios para comprender e interpretar. Low (1996) se refiere a esta falta de atención como The Lexical Invisibility Hypothesis.

En un estudio sobre la lectura de la atenuación en el nivel universitario, Hyland (2000a) descubrió que, en general, los estudiantes no identifican las estrategias de atenuación. Además, 
cuando las identifican, difícilmente les atribuyen un valor o una función relevante, que incidan en la interpretación final. Así, los estudiantes fueron incapaces de identificar las funciones de la atenuación en la interacción entre escritor, lector, texto, contexto o las convenciones de los géneros académicos y las comunidades discursivas. Por el contrario, Crismore y Vande Kopple (1997a, 1997b) y Lewin (2005) señalan que los estudiantes reconocen la atenuación cuando leen. Crismore y Vande Kopple (1997a, 1997b) hallaron en sendos estudios que los lectores no solo identificaban las estrategias de atenuación sino que, además, se veían afectados por estas, por lo que tomaban conciencia de su existencia y de su función textual. Lewin (2005), por su parte, encontró que al leer, los estudiantes identificaban los atenuadores, si bien estos no solían coincidir ni con los que los escritores habían reconocido haber usado conscientemente ni con los que los lingüistas identificaban en su análisis.

Con base en estos aportes, Réfega (2001) incorporó el estudio de la atenuación en un curso de lectura académica en una escuela universitaria de agricultura en Portugal. El curso consistió, fundamentalmente, en estimular a los estudiantes a que tomaran conciencia del uso de los atenuadores como estrategia para modular la certidumbre del contenido. Esta autora concluye que familiarizar a los estudiantes con el uso de las estrategias de atenuación podría facilitar la lectura de textos académicos.

\section{Metodología}

El hecho de que no exista investigación previa sobre la interpretación de la atenuación en contextos auténticos nos ha llevado a desarrollar instrumentos de análisis novedosos, que detallamos a continuación. Si bien esta investigación se basa en las respuestas obtenidas a partir de cuestionarios de preguntas cerradas y abiertas y aporta datos cuantitativos, hemos puesto el acento en el análisis cualitativo de las interpretaciones que dan los informantes para cada estrategia de atenuación. A continuación, detallamos a) los informantes, b) el contexto universitario, c) el artículo de revisión elegido, d) los atenuadores analizados, y e) los cuestionarios.

\subsection{Los informantes}

Trabajamos con 25 estudiantes de nuevo ingreso en la Facultad de Odontología de la Universidad de Los Andes, Mérida, Venezuela (FOULA, a partir de ahora), cursantes de la asignatura "Lectoescritura". Seleccionamos de forma aleatoria estos 25 informantes entre los 125 matriculados en el curso 2006-07: elegimos un estudiante cada 5 siguiendo el orden alfabético. El número de informantes es suficiente para garantizar la fiabilidad y la validez de los resultados, puesto que no se persigue obtener representatividad. 


\subsection{El contexto universitario}

La asignatura "Lectoescritura" forma parte del bloque curricular obligatorio "Introducción a la investigación". En 1999 la FOULA introdujo un modelo curricular novedoso, con cambios significativos desde el punto de vista pedagógico, filosófico, discursivo y metodológico, que persiguen la formación integral del odontólogo, tanto en la práctica clínica como en la producción y comprensión de conocimientos, como se fundamenta más arriba. Este modelo toma como eje central la "Práctica Odontológica Integral", tiene naturaleza comunitaria y multidisciplinaria y se organiza a partir de líneas y bloques curriculares (Morales \& Espinoza, 2001). La línea "Investigación" está constituida por cinco bloques (ver Cuadro 1) compuestos de estas disciplinas: "Metodología de la Investigación", "Computación", "Lectoescritura" e "Inglés", que imparte profesorado especialista en cada área junto con odontólogos.

En este contexto, la enseñanza de la investigación incluye la comprensión (en español y en inglés) y producción de textos académicos, científicos y profesionales; el dominio de las tecnologías del campo, y la adquisición de las metodologías propias para llevar a cabo procesos de investigación. Se enfatizan los distintos géneros utilizados en la comunidad odontológica, escritos para ser leídos (monografía, proyecto e informes de investigación, trabajo de grado, tesis, artículo de investigación y de divulgación, reporte de caso clínico, artículo de revisión, cartel) y escritos para ser escuchados (conferencia, ponencia, charla, taller, etc. Morales, Tona \& Tono, 2007), como muestra este cuadro:

Cuadro 1. Línea curricular "Investigación", con sus bloques, tipos de investigación y géneros discursivo (Morales, Tona \& Tono, 2007).

\begin{tabular}{|c|l|l|l|}
\hline Año & \multicolumn{1}{|c|}{ Bloque curricular } & \multicolumn{1}{|c|}{ Tipo de investigación } & \multicolumn{1}{|c|}{ Géneros discursivos } \\
\hline $1^{\circ}$ & $\begin{array}{l}\text { Introducción a la } \\
\text { investigación }\end{array}$ & Investigación documental & Monografía \\
\hline $2^{\circ}$ & Investigación Social & Investigación acción & $\begin{array}{l}\text { Proyecto e informe de } \\
\text { investigación }\end{array}$ \\
\hline $3^{\circ}$ & Investigación Epidemiológica & Investigación epidemiológica & Informe de investigación \\
\hline $4^{\circ}$ & $\begin{array}{l}\text { Investigación Biopatológica, } \\
\text { Clínica y Operativa }\end{array}$ & $\begin{array}{l}\text { Investigación acción, } \\
\text { epidemiológica, clínica, estudios } \\
\text { observacionales, experimentales }\end{array}$ & $\begin{array}{l}\text { Proyecto e informe de } \\
\text { investigación }\end{array}$ \\
\hline $5^{\circ}$ & Trabajo Especial de Grado & Libre elección & $\begin{array}{l}\text { Proyecto e informe de } \\
\text { investigación }\end{array}$ \\
\hline
\end{tabular}

En resumen, esta investigación se realizó en este marco curricular, en la materia de "Lectoescritura", del bloque "Introducción a la investigación", que versa sobre la investigación documental y que exige a los estudiantes leer numerosos AR y producir una monografía académica, que es un 
género parecido al AR. El hecho de que los informantes lean un texto auténtico de su disciplina en un contexto académico real y pertinente refuerza el carácter ecológico de la investigación, en el sentido de que los datos obtenidos proceden de las prácticas habituales que hacen los estudiantes informantes.

\subsection{El artículo de revisión}

Los informantes debían leer, como parte de la investigación, el AR titulado "Microorganismos de la placa dental relacionados con la etiología de la periodontitis". Este tiene 3.400 palabras y se publicó en 2004 en la revista Acta Odontológica Venezolana (véase Anexos). Se trata de un texto prototípico de Odontología (Morales et al., 2006), elaborado por autores con trayectoria reconocida en los boletines odontológicos. Acta Odontológica Venezolana tiene una trayectoria de más de 40 años como boletín científico y posee el respaldo y reconocimiento académico en Latinoamérica y, especialmente, en Venezuela; está incluida en índices biomédicos reconocidos mundialmente como: Scielo, Latindex, Lilacs, Livecs, Medline, PubMed, Biological Abstracts y US Nacional Library of Medicine. Según informantes expertos, el AR elegido tiene un nivel de dificultad apropiado para estudiantes de primer año.

\subsection{Los atenuadores usados}

Utilizamos cuatro tipos de atenuación, que ejemplifican las diferentes dimensiones lingüísticas en que se manifiesta este recurso: semántica, referido al grado de certidumbre de lo expresado; retórica, referida a la selección de las formas para argumentar; pragmática, referida al compromiso del autor con lo dicho y, sociocognitiva, referida a la imagen del autor, del lector y a su relación con la comunidad discursiva. El siguiente cuadro presenta los tipos, las dimensiones, las unidades y los autores que previamente habían estudiado estas formas de atenuación. 
Cuadro 2. Atenuadores usados en los fragmentos que los estudiantes debían interpretar.

\begin{tabular}{|c|c|c|c|}
\hline Tipo & Dimensión & Unidades & Autores \\
\hline Aproximadores & $\begin{array}{l}\text { Retórico- } \\
\text { semántica }\end{array}$ & $\begin{array}{l}\text { Predominantemente, principalmente, algunos, } \\
\text { oscila, frecuentemente, muchas veces, común- } \\
\text { mente, otros, ciertas. }\end{array}$ & \multirow{2}{*}{$\begin{array}{l}\text { Prince et al. (1982); } \\
\text { Salager-Meyer (1994) }\end{array}$} \\
\hline Escudos & $\begin{array}{l}\text { Retórico- } \\
\text { pragmática, } \\
\text { sociocognitiva }\end{array}$ & Probable, pueden, parecen. & \\
\hline $\begin{array}{l}\text { Construcciones } \\
\text { impersonales }\end{array}$ & $\begin{array}{l}\text { Retórico- } \\
\text { pragmática y } \\
\text { sociocognitiva }\end{array}$ & $\begin{array}{l}\text { Desagentivación: Según estudios, esta hipótesis } \\
\text { propone, han existido, expresadas por diferen- } \\
\text { tes investigadores. } \\
\text { Pasivas: fue descrita, estas entidades han sido } \\
\text { relacionadas, es la aceptada, son detectados, } \\
\text { han sido asociados, son considerados. } \\
\text { Impersonales: se discutió, algunos, se describe. }\end{array}$ & $\begin{array}{l}\text { Luukka \& Markkanen } \\
\text { (1997); Salager- } \\
\text { Meyer \& Defives } \\
\text { (1998); Oliver del O. } \\
\text { (2004). }\end{array}$ \\
\hline $\begin{array}{l}\text { Deícticos } \\
\text { temporales }\end{array}$ & $\begin{array}{l}\text { Semántica y } \\
\text { pragmática }\end{array}$ & Actualmente, recientemente. & $\begin{array}{l}\text { Morales, Cassany y } \\
\text { González (2007) }\end{array}$ \\
\hline
\end{tabular}

\subsection{Los cuestionarios}

Después de leer el AR mencionado, los informantes respondieron a dos cuestionarios de forma sucesiva: completaron al segundo después de haber consignado el primero. Antes de la investigación, los informantes no habían recibido instrucción universitaria previa sobre el AR, la atenuación o la lectura crítica; tampoco hubo ningún tipo de instrucción para responder a las preguntas (a excepción de las indicaciones introductorias de cada cuestionario).

\subsubsection{Primer cuestionario}

El objetivo del primer cuestionario (ver Anexos) es conocer si los informantes identifican espontáneamente la atenuación. Esto implica determinar si atribuyen a los fragmentos destacados alguna de las funciones de la atenuación, descritas en el marco teórico. Consta de 20 preguntas abiertas; cada una solicita la interpretación de un fragmento del AR en el que se emplea una o dos estrategias de atenuación. El informante debe escribir su interpretación del fragmento en cuestión, como muestra este ejemplo:

9) ¿Cómo interpreta la siguiente frase: "El crecimiento y reproducción de los microorganismos adheridos sobre la película, pueden conducir a la formación de la placa dental madura"? (p. 3, 38-40).

Para valorar las respuestas hemos distinguido si la interpretación dada identifica el valor de la estrategia atenuadora, si lo omite o si lo aumenta. Entendemos que la respuesta ideal sería que 
se interpretara el fragmento de manera similar a como lo hace la comunidad científica correspondiente, según la literatura reseñada y el testimonio de los informantes expertos.

Considerando las cuatro categorías descritas en el apartado anterior, la distribución de los atenuadores en el cuestionario quedó de la siguiente manera: 8 preguntas contenían aproximadores; 5, escudos; 10, alguna forma de impersonalidad y, 3, deícticos temporales. (Recordemos que algunas preguntas incluían más de un atenuador).

\subsubsection{Segundo cuestionario}

El objetivo del segundo cuestionario es averiguar cuáles de los tipos de atenuación reseñados son más conocidos y cómo se interpretan. Consta de 16 preguntas referidas a los cuatro tipos de atenuación, distribuidas de este modo: 5 aproximadores, 4 escudos, 5 impersonales y 2 deícticos. En cada pregunta se dan 5 opciones de respuesta: una paráfrasis precisa del fragmento atenuado (respuesta correcta); tres distractores que exploran interpretaciones erróneas, que cumplen con las condiciones habituales que deben tener los distractores en preguntas de elección múltiple (sintaxis equivalente, extensión parecida, plausibilidad pragmática, etc.), y un campo abierto donde el informante podría formular su propia interpretación. Veamos un ejemplo:

3) ¿Cómo interpreta el uso de la palabra "principalmente" en el siguiente fragmento: "... está constituida principalmente por flora bacteriana proteolítica Gram negativa en la cual se encuentran microorganismos periodontopatogénicos ${ }^{1,6,7}$ ? (p. 2, 4-5).

1. No tiene otros elementos constituyentes.

\section{Distractor}

2. Hay otros, pero los autores no los conocen.

Distractor

3. No es relevante indicar cuál es la cantidad exacta. Apropiada

4. Los otros elementos son inofensivos. Distractor

5. Otro (indique)

Para obtener una interpretación adecuada, pedimos previamente a tres odontólogos que, como informantes expertos, respondieran a ambos tests y atendieran a una entrevista para razonar sus respuestas. Las interpretaciones de los informantes coincidieron entre sí y también con la literatura teórica sobre la atenuación, lo cual valida estos instrumentos de investigación. 


\section{Resultados y discusión ${ }^{2}$}

\subsection{Primer cuestionario: identificación de la atenuación}

Los 25 informantes respondieron a todas las preguntas del primer cuestionario ( 500 respuestas en total) de dos maneras: con paráfrasis en las que se simula la voz del autor del AR; y con explicaciones en las que "habla" el propio informante. En ambos casos, se consideran sobre todo aspectos conceptuales de la disciplina odontológica (significados de palabras, por ejemplo), algunos elementos gramaticales (la parte de la oración o la función sintáctica) y atenuadores asociados predominantemente a la dimensión semántica (aproximadores). De forma general, se omitieron las estrategias asociadas a la dimensión pragmática y socio-cognitiva, lo cual sugiere que no realizaron una lectura crítica, pues leyeron solo lo explícito (Cassany, 2003, 2005, 2006a, 2006b).

Por otro lado, tomando como referencia el total de posibles respuestas $(25 \times 20=500)$, los resultados generales, descritos en el Gráfico 1, muestran que la atenuación fue reconocida en el 30\% de las respuestas (150), fue suprimida en el $40 \%$ (200) y fue aumentada en un $30 \%$ (150).

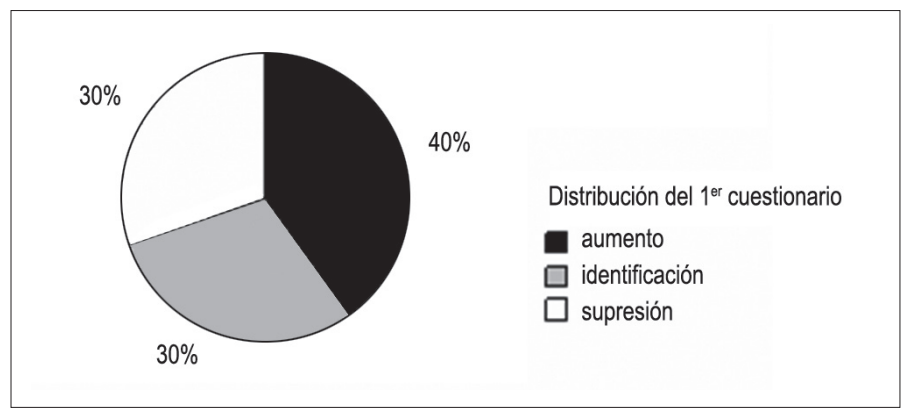

Gráfico 1. Distribución del primer cuestionario.

\subsubsection{Reconocimiento de la atenuación}

Como puede observarse en el Gráfico 1, en el 30\% de las respuestas se identifica la atenuación empleada en el fragmento. Esto coincide con los resultados de Crismore y Vande Kopple (1997a, 1997b) y Lewin (2005), quienes encontraron que los estudiantes reconocen la atenuación cuando leen. Veamos algunos ejemplos: 
En el siguiente ejemplo ${ }^{3}$, tomado de la respuesta a la pregunta 8 , se observa que aunque el verbo modal epistémico "poder" se transforma en un adjetivo epistémico (posible), la atenuación se mantiene puesto que ambas formas ejercen una función similar.

\begin{tabular}{|l|l|}
\hline \multicolumn{1}{|c|}{ Original } & \multicolumn{1}{c|}{ Interpretación } \\
\hline $\begin{array}{l}\text { El crecimiento y reproducción de los } \\
\text { microorganismos adheridos sobre la película, } \\
\text { pueden conducir a la formación de la placa dental } \\
\text { madura. }\end{array}$ & $\begin{array}{l}\text { Que la placa dental madura es el posible resultado } \\
\text { de los procesos que pasan los microorganismos que } \\
\text { se encuentran en la película. }\end{array}$ \\
\hline
\end{tabular}

En la pregunta 19, la impersonalidad original, que permite al autor disminuir su compromiso con lo enunciado, se parafrasea con otra estrategia atenuadora: el verbo modal epistémico "poder":

\begin{tabular}{|c|c|}
\hline Original & Interpretación \\
\hline $\begin{array}{l}\text { Además de los factores nombrados anteriormente, } \\
\text { Wolff (1994); Genco (1996); Fleming (1999); } \\
\text { Marsh y Martin (2000); Lindhe (2000), señalan que } \\
\text { ciertas bacterias como Porphyromonas gingivalis, } \\
\text { Prevotella intermedia, Prevotella nigrescens, } \\
\text { Prevotella loescheii, Fusobacterium nucleatum, } \\
\text { Bacteroides forsythus, Campylobacter rectus, } \\
\text { Eikenella corrodens y Treponema sp., han sido } \\
\text { comúnmente implicadas con la periodontitis y son } \\
\text { consideradas como indicadores de riesgo para la } \\
\text { progresión de dicha enfermedad 2,26,28,29,30. }\end{array}$ & $\begin{array}{l}\text { Además de los factores de riesgo mencionados } \\
\text { anteriormente también existen ciertas bacterias } \\
\text { que pueden ocasionar el desarrollo de la } \\
\text { periodontitis. }\end{array}$ \\
\hline
\end{tabular}

En la siguiente paráfrasis se atenúa empleando el mismo verbo del original, de modalidad epistémica:

\begin{tabular}{|l|l|}
\hline \multicolumn{1}{|c|}{ Original } & \multicolumn{1}{|c|}{ Interpretación } \\
\hline $\begin{array}{l}\text { Por otra parte, investigaciones realizadas por } \\
\text { Botero y col. (1995); Genco (1996); Umeda y } \\
\text { col.(1998); Fleming (1999) establecen que existen } \\
\text { una serie de factores de riesgo que pueden } \\
\text { predisponer a los individuos a desarrollar esta } \\
\text { enfermedad, tales como sexo, raza (...) }\end{array}$ & $\begin{array}{l}\text { Otros investigadores proponen que existen una serie } \\
\text { de factores que pueden influir en el desarrollo de } \\
\text { esta enfermedad como lo son el sexo, la raza, etc. }\end{array}$ \\
\hline
\end{tabular}

En la pregunta 2 se sustituye el deíctico temporal "actualmente" con una expresión similar: 


\begin{tabular}{|l|l|}
\hline \multicolumn{1}{|c|}{ Original } & \multicolumn{1}{c|}{ Interpretación } \\
\hline $\begin{array}{l}\text { Actualmente, Marsh y Martin (2000), definen a } \\
\text { la placa dental como una comunidad microbiana } \\
\text { compleja que se encuentra en la superficie de } \\
\text { los dientes, embebida en una matriz de origen } \\
\text { bacteriano y salival. }\end{array}$ & $\begin{array}{l}\text { Hoy en día según Marsh y Martín, la placa dental se } \\
\text { define como un grupo de gérmenes complicados que } \\
\text { se localizan en el área de los dientes, empapada } \\
\text { con un órgano bacteriano salival. }\end{array}$ \\
\hline
\end{tabular}

La pregunta 3 muestra un ejemplo prototípico de la identificación de un aproximador:

\begin{tabular}{|l|l|}
\hline \multicolumn{1}{|c|}{ Original } & \multicolumn{1}{c|}{ Interpretación } \\
\hline La placa dental supragingival se encuentra & La placa dental crece en las superficies exteriores \\
en las superficies dentales y está constituida & de los dientes y debajo de las orillas de las encías, \\
predominantemente por flora bacteriana & la misma se compone principalmente de bacterias, \\
sacarolítica Gram positiva, en las cuales se & alimentos y saliva formando el sarro; dando origen \\
encuentran microorganismos cariogénicos. & a microbios (caries). \\
\hline
\end{tabular}

En la pregunta 5 (¿Por qué los autores usaron el verbo oscilar en la frase "...oscila entre 0,1 y 1,0 micrómetros de espesor..."?), el aproximador, expresado por medio del verbo "oscilar", fue interpretado como una expresión de honestidad, en la que el autor indica que no puede afirmar categóricamente por la variabilidad de los datos o por limitaciones de los resultados. Esto coincide con los resultados de estudios previos sobre el uso de atenuadores en el discurso médico (Salager-Meyer, 1994; Salager-Meyer \& Defives, 1998). Veamos algunas de estas interpretaciones:

- "Los autores usaron el verbo oscilar para señalar que sobre la superficie del esmalte comienza a depositarse una película delgada, amorfa que puede desplazarse entre 0,1 y 1,0 micrómetros de espesor".

- " "Hay una variación con respecto al espesor, por lo tanto no se toma un valor estándar".

- "Porque no es una medida exacta para cada caso, sino que varía de un caso a otro. Por eso utilizan un parámetro para abarcar todas las medidas posibles.

- "Porque no es una medida exacta, es como un promedio; no se puede determinar con exactitud su espesor sino que varía entre esta proporción, cabe destacar que estas variaciones pueden ser causadas por la intervención de diferentes agentes ya sean internos o externos, como en el caso de la formación de la placa bacteriana".

\subsubsection{Supresión u omisión de la atenuación}

Como también se observa en el Gráfico 1, en el $40 \%$ de las repuestas no se reprodujo la estrategia de atenuación; los informantes no hicieron referencia a los aspectos semánticos, pragmáticos, socio-cognitivos o retóricos relacionados con la atenuación. Al parafrasear, suprimieron 
los atenuadores y produjeron "textos fácticos, objetivos" (Crismore \& Vande Kopple, 1997a), en los que las proposiciones eran presentadas como hechos, no como opiniones. Estos resultados coinciden con Low (1996) y Hyland (2000a), quienes encontraron que los estudiantes participantes de sus estudios fueron incapaces de notar la atenuación; estos dispositivos pasaban inadvertidos. Desde esta perspectiva, la lectura se limita al componente semántico conceptual; se omiten aspectos implícitos fundamentales para la comprensión del escrito (Hyland, 1994; Fortanet et al., 2001).

En el siguiente ejemplo la expresión atenuada por medio de un aproximador, en la que se expresaba la variabilidad en la constitución de la placa dental, se transformó en una afirmación con alto nivel de certidumbre:

\begin{tabular}{|l|l|}
\hline \multicolumn{1}{|c|}{ Original } & \multicolumn{1}{c|}{ Interpretación } \\
\hline $\begin{array}{l}\text { La placa dental supragingival se encuentra } \\
\text { en las superficies dentales y está constituida } \\
\text { predominantemente por flora bacteriana } \\
\text { sacarolítica Gram positiva, en las cuales se } \\
\text { encuentran microorganismos cariogénicos. }\end{array}$ & $\begin{array}{l}\text { La placa dental supragingival esta hospedada en } \\
\text { la parte apical del diente, formada por bacterias } \\
\text { sacaroliticas de tipo Gram positivas, caracterizadas } \\
\text { por localizarse bacterias afines a la carie. }\end{array}$ \\
& \\
\hline
\end{tabular}

En las siguientes respuestas, una proposición atenuada por medio del verbo modal epistémico "poder", que presentaba una opinión y proyectaba modestia y humildad, fue parafraseada en forma de afirmaciones categóricas, presentadas como hechos:

\begin{tabular}{|l|l|}
\hline \multicolumn{1}{|c|}{ Original } & \multicolumn{1}{c|}{ Interpretaciones } \\
\hline El crecimiento y reproducción de los & - Los micro organismos se fijan comienzan a crecer \\
microorganismos adheridos sobre la película, & y a ser mas firmes en su agarre y con el tiempo se \\
pueden conducir a la formación de la placa dental & transforma es una placa dental madura. \\
madura. & $\begin{array}{l}\text { - El desarrollo progresivo de las bacterias que } \\
\text { yacen en la película ya formada, aceleran la }\end{array}$ \\
& $\begin{array}{l}\text { creación de la placa dental. } \\
\text { - El desarrollo de estos microorganismos conducen } \\
\text { a la formación de la placa dental madura }\end{array}$ \\
\hline
\end{tabular}

Algo similar ocurre con una respuesta a la pregunta 12, en la que se elimina el adverbio epistémico "predominantemente", con el que el autor proyectaba precaución al indicar la variabilidad de los datos y la imposibilidad de precisar, y se produce un enunciado fáctico: 


\begin{tabular}{|l|l|}
\hline \multicolumn{1}{|c|}{ Original } & \multicolumn{1}{c|}{ Interpretación } \\
\hline Slots (1979) señala, que las bacterias aisladas a & Slots (1979) describe, que los microorganismos \\
partir de individuos periodontalmente sanos son & que han sido erradicados en pacientes sanos \\
predominantemente cocos y bacilos facultativos & $\begin{array}{l}\text { periodontalmente, son de tipo cocos y bacilos } \\
\text { facultativos, Gram positivos. }\end{array}$ \\
\hline
\end{tabular}

Un número muy bajo consideró en su interpretación aspectos lingüísticos. Por ejemplo, en la siguiente respuesta a la pregunta 3 , la interpretación se limita a analizar morfológicamente la palabra "supragingival". Se percibe, en este caso, mayor interés por el componente conceptual asociado a la disciplina odontológica:

\begin{tabular}{|l|l|}
\hline \multicolumn{1}{|c|}{ Original } & \multicolumn{1}{c|}{ Interpretación } \\
\hline $\begin{array}{l}\text { La placa dental supragingival se encuentra } \\
\text { en las superficies dentales y está constituida } \\
\text { predominantemente por flora bacteriana }\end{array}$ & $\begin{array}{l}\text { Que a la placa llamada supragingival esta en la } \\
\text { superficie de los dientes lo que es de suponerse ya } \\
\text { que el sufijo supra es "en cima" o "arriba" dice } \\
\text { sacarolítica Gram positiva, en las cuales se } \\
\text { encuentran microorganismos cariogénicos. }\end{array}$ \\
\hline
\end{tabular}

En el siguiente caso, las construcciones impersonales, con las que el autor oculta al responsable de la proposición, se personalizan, atribuyéndoles la responsabilidad del contenido a los autores:

\section{Original}

Además de los factores nombrados anteriormente, Wolff (1994); Genco (1996); Fleming (1999);

Marsh y Martin (2000); Lindhe (2000), señalan que ciertas bacterias como Porphyromonas gingivalis, Prevotella intermedia, Prevotella nigrescens, Prevotella loescheii, Fusobacterium nucleatum, Bacteroides forsythus, Campylobacter rectus, Eikenella corrodens y Treponema sp., han sido comúnmente implicadas con la periodontitis y son consideradas como indicadores de riesgo para la progresión de dicha enfermedad 2,26,28,29,30.
Interpretación

Que a además de los factores mencionados Wolff (1994); Genco (1996); Fleming (1999); Marsh y Martin (2000); Lindhe (2000) dicen que las bacterias como: Porphyromonas gingivalis, Prevotella intermedia, Prevotella nigrescens, Prevotella loescheii, Fusobacterium nucleatum, Bacteroides forsythus, Campylobacter rectus, Eikenella corrodens y Treponema sp. también están presentes en la periodontitis y son factores de riesgo para que la enfermedad siga avanzando.

\subsubsection{Aumento de la atenuación}

En el 30\% de las respuestas (Gráfico 1), además de reproducir la estrategia de atenuación empleada en el original, los informantes aumentan la atenuación, "fertilizan los atenuadores" (Fertilizing hedges, para Bank, 1994: 587), incorporan otras formas, constituyendo a veces atenuadores compuestos o redundantes (Salager-Meyer, 1994; Salager-Meyer, Defives \& Hamelynck, 1996; Hyland, 1998b). El siguiente ejemplo enfatiza la falta de compromiso: 


\begin{tabular}{|l|l|}
\hline \multicolumn{1}{|c|}{ Original } & \multicolumn{1}{c|}{ Interpretación } \\
\hline $\begin{array}{l}\text { Los microorganismos P. gingivalis, P. intermedia, } \\
\begin{array}{l}\text { F. nucleatum, C. rectus y B. forsythus parecen } \\
\text { encontrarse en valores altos en sitios con pérdida } \\
\text { reciente de inserción (...) }\end{array}\end{array}$ & $\begin{array}{l}\text { Al parecer en las zonas donde existe perdida } \\
\text { reciente de inserción suelen encontrarse en } \\
\text { altos valores los microorganismos P. gingivalis, P. } \\
\text { intermedia. F. nucleatum, C. rectus y B. forsythus }\end{array}$ \\
\hline
\end{tabular}

En el siguiente caso, la paráfrasis acentúa la incertidumbre: el adjetivo epistémico de probabilidad se parafrasea usando el adjetivo y el nombre epistémico de posibilidad:

\section{Original}

En las ultimas fases de la formación de la placa, es probable que predomine la coagregación entre especies Gram negativas anaerobias, como F. nucleatum con $\mathrm{P}$. gingivalis ${ }^{14}$.

\section{Interpretación}

En los últimos procesos o etapas de la acumulación de la placa, es posible o hay posibilidades de que prevalezca la unión entre los géneros Gram negativas anaeróbicas, como $\mathrm{F}$. Nucleatum con P. Gingivalis, este fenómeno puede explicar las características de la interacción patogénica de las condiciones periodentales.

Así mismo, algunos participantes transformaron los atenuadores simples (escudos, construcciones impersonales, aproximadores y deícticos temporales) en compuestos ("redundancia de atenuación”, según Salager-Meyer et al, 1996). Ejemplo:

\begin{tabular}{|l|l|}
\hline \multicolumn{1}{|c|}{ Original } & \multicolumn{1}{c|}{ Interpretación } \\
\hline $\begin{array}{l}\text { Los microorganismos P. gingivalis, P. intermedia, } \\
\begin{array}{l}\text { F. nucleatum, C. rectus y B. forsythus parecen } \\
\text { encontrarse en valores altos en sitios con pérdida } \\
\text { reciente de inserción (...) }\end{array}\end{array}$ & $\begin{array}{l}\text { Los microorganismos antes mencionados, se cree } \\
\text { que pueden encontrarse en altos valores en zonas } \\
\text { con perdida inminente de inserción. }\end{array}$ \\
\hline
\end{tabular}

En el siguiente ejemplo, el verbo modal epistémico se combinó con una desagentivación, transformando un aproximador en un atenuante compuesto:

\begin{tabular}{|c|c|}
\hline Original & Interpretación \\
\hline $\begin{array}{l}\text { No obstante otros factores inherentes a los } \\
\text { individuos, como algunas enfermedades genéticas } \\
\text { o por razones adquiridas como habito de fumar, } \\
\text { escasa higiene bucal, entre otros, permitirán que } \\
\text { ciertas bacterias específicas patógenas aumenten } \\
\text { en número (...) }\end{array}$ & $\begin{array}{l}\text { Algunas enfermedades genéticas pueden ser } \\
\frac{\text { consideradas como causantes de la multiplicación }}{\text { de ciertas bacterias. }}\end{array}$ \\
\hline
\end{tabular}

\subsection{Segundo cuestionario: funciones de las estrategias de atenuación}

Las 16 preguntas del segundo cuestionario incluyen 5 ítems relacionados con los aproximadores, 4 con los escudos, 2 con los deícticos temporales y 5 con las construcciones impersonales. Todos 
los informantes respondieron a todas las preguntas, de modo que obtuvimos 400 respuestas. Puesto que el propósito del cuestionario es evaluar el conocimiento de cada tipo de atenuación (y no la competencia del informante), organizamos las respuestas por estrategia de atenuación.

\subsubsection{Aproximadores}

El Gráfico 2 muestra que, del total de respuestas relacionadas con los aproximadores (125), el 80\% (100 respuestas) fueron apropiadas: los informantes asociaron esta estrategia de atenuación predominantemente con la indicación de variabilidad de los datos o con el establecimiento de los márgenes posibles de interpretación, lo cual supone proyectar honestidad en la escritura académica. Esto coincide con los resultados de Salager-Meyer (1994), Salager-Meyer y Defives (1998) y Oliver (2004), que encontraron que los autores de artículos médicos hispanos y anglosajones usan esta estrategia para proyectar honestidad. También relacionaron el uso de esta estrategia con la falta de claridad e imprecisión, ya sea por falta de información o la ausencia de datos precisos.

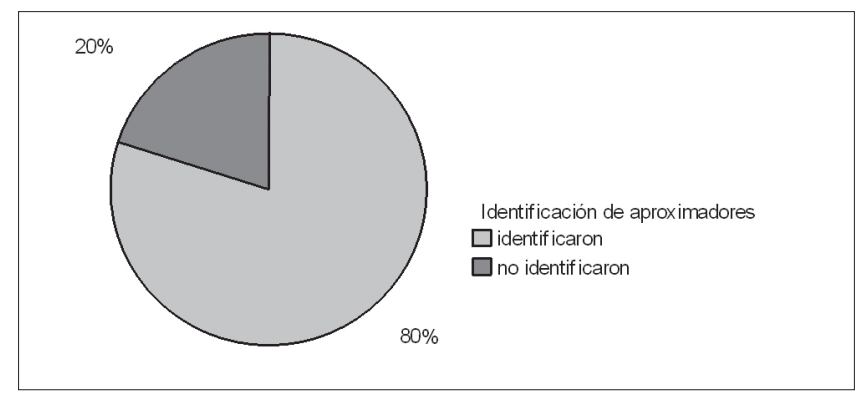

Gráfico 2. Identificación de aproximadores.

\subsubsection{Escudos}

Tal como puede observarse en el Gráfico 3, solo un porcentaje muy bajo de respuestas relacionadas con los escudos (15 de 100) identificó la dimensión retórico-pragmática asociada al uso de este tipo de atenuadores. 


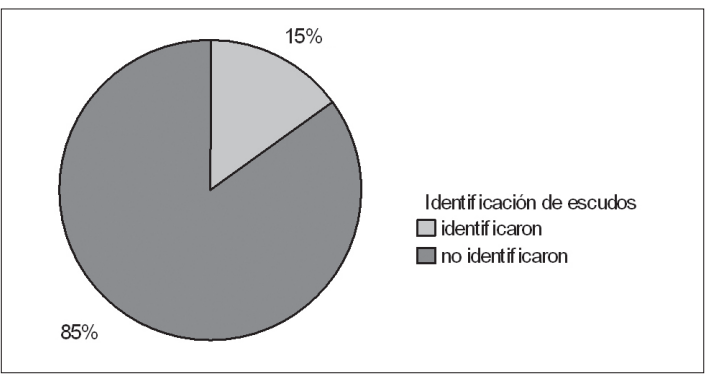

Gráfico 3. Identificación de escudos.

En la mayoría de los casos, no se consideró como atenuante el verbo modal epistémico "poder", uno de los escudos más empleados en el discurso científico para expresar incertidumbre, tentatividad y falta de compromiso con lo dicho. En cambio, los informantes lo asociaron con el modal deóntico que expresa capacidad (que no consideraríamos una estrategia de atenuación; SalagerMeyer, 1994).

Así mismo, no identificaron la función de los escudos de presentar las afirmaciones polémicas con precaución, previniendo críticas y reacciones negativas de la comunidad, aunque sean bastante frecuentes en el discurso biomédico (Salager-Meyer et al., 1996). Tampoco lograron asociar el uso de escudos para evadir afirmaciones absolutas y negociar con la comunidad discursiva la aceptación de las conclusiones, es decir, presentar las afirmaciones como opiniones y no como hechos.

En 9 respuestas, se relacionó el uso de escudos con la falta de información, desconocimiento o inseguridad para afirmarlo categóricamente, lo cual podría interpretarse como una estrategia de proyección de honestidad.

\subsubsection{Deícticos temporales}

Solo en el 30\% de las respuestas asociadas a los deícticos temporales (15 de 50) se identificó el uso de esta estructura como estrategia para proyectar tentatividad del conocimiento científico. Con este tipo de atenuante se abre la posibilidad de que un determinado problema se haya interpretado de manera distinta a la actual y de que en el futuro haya interpretaciones y aplicaciones distintas e igualmente válidas (Morales, Cassany \& González, 2007). Con esto se evita la arrogancia y se negocia la aceptación de la comunidad de sus proporciones. Salager-Meyer et al. (1996) encontraron que una de las funciones más frecuentes de la atenuación es expresar la 
naturaleza provisional de las proposiciones. Al contrario, la mayoría de informantes asoció los deícticos temporales con la información de actualidad, nueva, de reciente publicación.

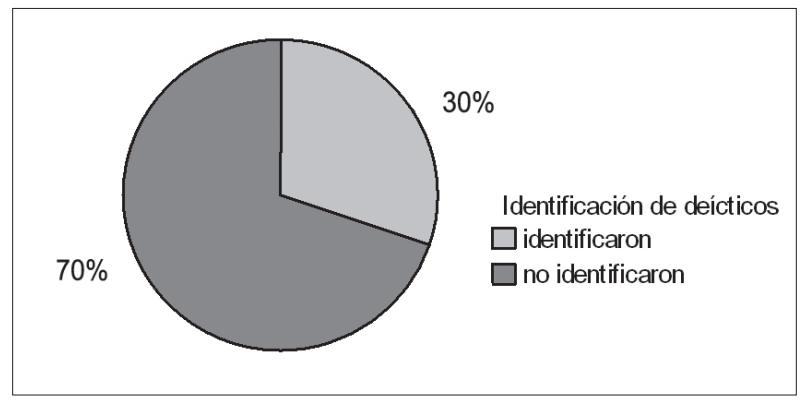

Gráfico 4. Identificación de deícticos.

\subsubsection{Construcciones impersonales}

112 respuestas (de las 125 posibles, asociadas a la impersonalidad, cerca del 90\%), indicaron que las construcciones impersonales se usan para omitir la referencia a la cita, ya sea porque es irrelevante o porque no se dispone de la información. Esto supone, de alguna manera, desconocimiento de la cultura académica en relación con los mecanismos de interdiscursividad.

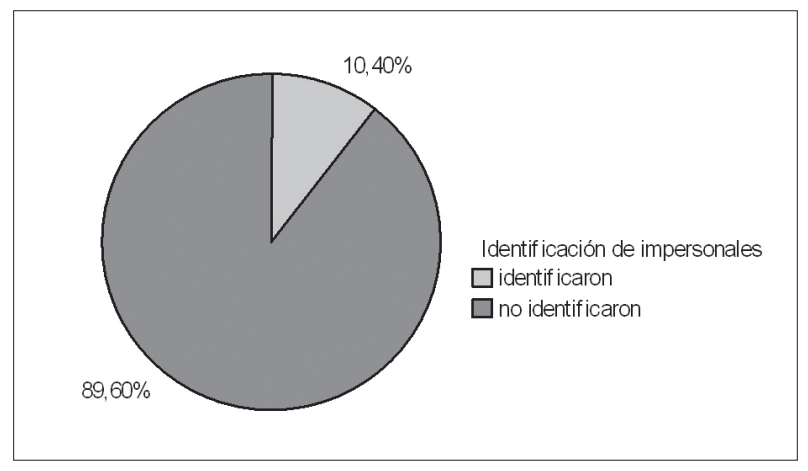

Gráfico 5. Identificación de impersonales.

Como se observa en el Gráfico 5, solo cerca del 10\% de informantes seleccionó la opción correcta, es decir, asoció el uso de los impersonales con el cumplimiento de una de las convenciones de 
la prosa científica: bajar el tono de las afirmaciones, evadir la responsabilidad de la proposición y ocultar el agente responsable y, de esa forma, evitar críticas potenciales. Esto concuerda con los resultados de Low (1996) y Hyland (2000a).

\section{CONCLUSIONES}

En el AR, los autores transmiten no solo contenidos proposicionales sino también sus propias perspectivas sobre la verdad de las proposiciones que enuncian y sobre sus lectores. Por lo tanto, leer y comprender críticamente un AR implica no solo comprender el contenido proposicional, sino también identificar e interpretar las formas y funciones de la atenuación (en su dimensión socio-cognitiva, pragmática y retórica), como elemento relevante en ese género discursivo.

En este sentido, los resultados de este estudio sugieren que los informantes estudiados no han identificado ni interpretado las dimensiones retóricas, pragmáticas y sociocognitivas relacionadas con la atenuación, por lo que no puede afirmarse que hayan comprendido totalmente el texto utilizado en la investigación. Se percibe que la información del texto y los conocimientos previos de los lectores no fueron suficientes para generar las interpretaciones que probablemente pretendía transmitir el autor, de acuerdo con los estudios previos sobre la atenuación y con los odontólogos expertos que validaron los cuestionarios. La mayoría de los estudiantes $(60 \%)$ identificó, actualizó y parafraseó, de alguna manera, la atenuación estudiada, pero predominó el componente semántico, obviando notablemente las dimensiones pragmáticas, retóricas y sociocognitivas.

El predominio de la dimensión semántica en las interpretaciones puede estar asociado a las escasas experiencias previas de lectura de textos científicos de los estudiantes y, en definitiva, a los escasos referentes de la comunidad discursiva que poseen. El hecho de que cerca de $40 \%$ de los participantes haya eliminado la atenuación al parafrasear los enunciados podría sugerir cierta dificultad para identificar niveles de certidumbre del contenido, niveles de compromiso del autor, y para diferenciar entre opiniones, evaluaciones y hechos en el discurso científico.

En última instancia, estos resultados también apuntan datos sobre la representación que los informantes tienen de la ciencia, del discurso y de su proceso de construcción. La incapacidad (parcial) para reconocer el valor de la atenuación apunta hacia una concepción simplista del discurso científico, como expresión semántica transparente de un saber disciplinario establecido, cerrado, independiente de los autores y los lectores. Esta concepción dista mucho de la mirada más sociocultural que subyace a la investigación discursiva sobre la atenuación, que concibe el conocimiento científico como un proceso de construcción social, en el que el autor negocia con sus pares la aceptación de sus verdades. 
Por lo antes mencionado, los resultados presentan implicaciones didácticas. En primer lugar, evidencian la necesidad de abordar la lectura crítica de textos científicos auténticos en el ámbito universitario. Es necesario enseñar a los futuros odontólogos a leer lo que no se expresa explícitamente en el texto, pero que es igualmente importante para su comprensión. En segundo lugar, estudiar las posibles interpretaciones asociadas a la atenuación en las dimensiones pragmáticas, semánticas, retóricas y sociocognitivas podría facilitar su uso apropiado cuando los estudiantes tengan que escribir textos académicos y científicos, como los artículos de investigación y AR. Esto podría contribuir a que los estudiantes se incorporarán de manera más efectiva y rápida a su comunidad discursiva.

\section{AGRADECIMIENTOS}

Agradecemos a los informantes de este estudio (estudiantes de $1^{\circ}$ año de la Facultad de Odontología de la Universidad de Los Andes (ULA), Mérida, Venezuela, período 2006-2007) y al profesor José Rafael Tona Romero (responsable de la asignatura Lectoescritura) su participación y apoyo para llevar a cabo esta investigación. Así mismo, extendemos nuestro agradecimiento al Dr. Defrén Camejo Aguilar y al prof. Ernesto Marín, profesores e investigadores de la ULA, quienes participaron, junto con el prof. Tona Romero, como informantes especialistas en este estudio.

\section{REFERENCIAS BIBLIOGRÁFICAS}

Alcaraz, M. \& Salager-Meyer, F. (2002). Género y crítica en la prosa médica escrita en español: Función comunicativa y relación de poder. Hermes, 29, 163-186.

Alderson, J. (2000). Assessing reading. Cambridge: Cambridge University Press.

Banks, D. (1994). Hedges and how to trim them. En M. Brekke, I. Andersen, T. Dahl \& J. Myking (Eds.), Applications and implications of current LSP research (pp. 587-592). Bergen: Fakbokforlaget.

Caldeiro, M., Feliu, E., García, D., Herranz, G., Lience, E., Pulido, M., Ribera, M., Rey-Joly, C., Ruiz, F. \& Vilarroya, O. (1993). Manual de estilo. Publicaciones biomédicas. Barcelona: Mosby.

Candlin, C. \& Hyland, K. (1999). Writing: Texts, processes and practices. London: Longman.

Cassany, D. (2003). Aproximaciones a la lectura crítica: Teoría, ejemplos y reflexiones. Tarbiya, 32, 113-132.

Cassany, D. (2005). Los significados de la comprensión crítica. Lectura y Vida, 26(3), 32-45.

Cassany, D. (2006a). Leer tras las líneas. Sobre la lectura contemporánea. Barcelona: Anagrama.

Cassany, D. (2006b). Taller de textos: Leer, escribir y comentar en el aula. Barcelona: Paidós.

Crismore, A. \& Vande Kopple, W. (1997a). The effects of hedges and gender on the attitudes of rea- 
ders in the United States toward material in a science textbook. En A. Duszak (Ed.), Culture and styles of academic discourse (pp. 223-247). Berlin: W. de Gruyter.

Crismore, A. \& Vande Kopple, W. (1997b). Hedges and readers: Effects on attitudes and learning. En R. Markkanen \& H. Schröder (Eds.), Hedging and discourse: Approaches to the analysis of a pragmatic phenomenon in academic texts (pp. 83-114). Berlin: W. de Gruyter.

Day, R. (1990). Cómo escribir y publicar trabajos científicos. Washington, D.C.: OPS.

Eco, U. (1981). Lector in fábula. La cooperación interpretativa en el texto narrativo. España: Ediciones Lumen.

Fortanet, I., Palmer, J. \& Postiguillo, S. (2001). Hedging devices in technical and academic English. En J. Palmer, S. Posteguillo \& I. Fortanet (Eds.), Discourse analysis and terminology in languages for specific purposes (pp. 241-257). Castelló de la Plana: Universitat Jaume I.

Goodman, K. (1980a). Behind the eyes: What happens in reading. En H. Singer \& R. Ruddell (Eds.), Theoretical models and processes of reading (pp. 470-495). Newark, DE: International Reading Association.

Goodman, K. (1980b). Reading a psycholinguistic guessing game. En H. Singer \& R. Ruddell (Eds.), Theoretical models and processes of reading (pp. 497-508). Newark, DE: International Reading Association.

Goodman, K. (1994). Reading, writing, and written texts: A transactional sociopsycholinguistic view. En R. Ruddell, M. Ruddell \& H. Singer (Eds.), Theoretical models and processes of reading (pp. 1093-1131). Newark, DE: International Reading Association.

Goodman, K. (2005). La lectura. Un mismo proceso. Conferencia presentada en VIII Congreso Latinoamericano para el Desarrollo de la Lectura y La Escritura, San Juan, Puerto Rico.

Greimas. A. (1983). La semiótica del texto. Ejercicios prácticos: Análisis de un cuento de Maupassant. Barcelona: Paidós.

Greimas. A. \& Courtés, J. (1982). Semiótica: Diccionario razonado de la teoría del lenguaje. Madrid: Gredos.

Hyland, K. (1994). Hedging in academic writing and EAP textbooks. English for Specific Purposes, 13(3), 239-256.

Hyland, K. (1998a). Boosting, hedging and the negotiation of academic knowledge. Text, 18, 349-382.

Hyland, K. (1998b). Hedging in scientific research articles. Amsterdam: Benjamins.

Hyland, K. (2000a). Hedges, boosters and lexical invisibility: Noticing modifiers in academic texts. Language Awareness, 9, 179-197.

Hyland, K. (2000b) Disciplinary discourses. Social interaction in academic writing. London: Longman.

Hyland, K. (2001). Humble servant of the discipline? Self-mention in research articles. English for Specific Purposes, 20(3), 2007-226. 
Jackson, L., Meyer, W. \& Parkinson, J. (2006). A study of the writing tasks and reading assigned to undergraduate science students at a South African university. English for Specific Purposes, 25(3), 260-281.

Lakoff, G. (1972). Hedges: A study in meaning criteria and the logic of fuzzy concepts. En P. Peranteau, J. Levi \& G. Phares (Eds.), Papers from the eighth regional meeting Chicago Linguistic Society (pp. 183-228). Chicago: Chicago Linguistic Society.

Lewin, B. (2005). Hedging: An exploratory study of authors' and readers' identification with 'toning down" in scientific texts. English for Specific Purposes, 24(4), 163-178.

Low, G. (1996) Intensifiers and hedges in questionnaire items and the lexical invisibility hypothesis. Applied Linguistics, 17, 1-37.

Luukka, M. \& Markkanen, R. (1997). Impersonalization as a form of hedging. En R. Markkanen \& H. Schröder (Eds.), Hedging and discourse. Approaches to the analysis of a pragmatic phenomenon in academic texts (pp. 168-187). Berlin: W. de Gruyter.

Markkanen, R. \& Schröder, H. (1997). Hedging: A challenger for pragmaticis and discourse analysis. En R. Markkanen \& H. Schröder (Eds.), Hedging and discourse. Approaches to the analysis of a pragmatic phenomenon in academic texts (pp. 3-18). Berlin: W. de Gruyter.

Markkanen, R., \& Schröder, H. (1989). Hedging as a translation problem in scientific texts. En C. Laurén \& M. Nordman (Eds.), Special Languages: From human thinking to thinking machines (pp. 171-179). Vaasa: University of Vaasa.

Mendiluce Cabrera, G. \& Hernández Bartolomé, A. (2005). La matización asertiva en el artículo biomédico: Una propuesta de clasificación para los estudios contrastivos inglés-español. Ibérica, 10, 63-90.

Morales, 0. \& Espinoza, N. (2001). El desarrollo de la lectura y la escritura en la universidad. Una experiencia de integración docente. En $2^{\circ}$ Simposio Internacional de "Lectura y Vida [Versión en CDROM]. Buenos Aires, Argentina: Asociación Internacional de Lectura/Lectura y Vida.

Morales, O. \& Espinoza, N. (2005). El desarrollo de la escritura de estudiantes universitarios. Lectura y Vida, 25(2), 13-27.

Morales, O. González, C. \& Tona, J. (2006). Análisis discursivo de artículos de revisión odontológicos publicados en revistas iberoamericanas entre 1995 y 2005: Estudio exploratorio. En M. PérezLlantada, R. Plo Alastrué \& C. Neumann (Eds.), Actas del V Congreso Internacional AELFE. Zaragoza: Universidad de Zaragoza.

Morales, O., Cassany, D. \& González, C. (2007). La atenuación en artículos de revisión odontológicos publicados en español entre 1994 y 2004: Estudio exploratorio. Revista Ibérica, 14, 33-58.

Morales, O., Tona, J. \& Tonos, R. (2007). La enseñanza de la investigación en el contexto odontológico: La experiencia de la Facultad de Odontología de la Universidad de Los Andes. Revista Kaleidoscopio, 4(2), 5-18.

Myers, G. (1989). Pragmatic politeness in scientific articles. Applied linguistics, 10, 1-35. 
Myers, G. (1992). "In this text we report..." Speech acts and scientific facts. Journal of Pragmatics, 17, 295-313.

Oliver del Olmo, S. (2004). Análisis contrastivo español/inglés de la atenuación retórica en el discurso médico. El artículo de investigación en el caso clínico. Tesis doctoral, Universidad Pompeu Fabra, Barcelona, España [en línea]. Disponible en: http://www.tdx.cesca.es/TESIS_UPF/ AVAILABLE/TDX-1020105-124115//tsoo1de1.pdf

Oxman, A. D. (1994). Checklist for review articles. British Medical Journal, 309, 697-703.

Oxman, A. \& Guyatt, G. (1994). Guía para la lectura de artículos de revisión. En Organización Panamericana de la Salud (Ed.), Publicación científica. Aspectos metodológicos, éticos y prácticos en ciencias de la Salud (pp. 175-185). Washington, D.C.: Organización Panamericana de la Salud.

Parodi, G. (2004). Textos de especialidad y comunidades discursivas técnico-profesionales: Una aproximación basada en corpus computarizado. Estudios Filológicos, 39, 7-36.

Parodi, G. (2006). Comprender y aprender a partir de los textos: Aproximaciones al discurso especializado escrito en el ámbito técnico-profesional. Conferencia presentada en el III Congreso Internacional de español para fines específicos. "Del concepto al texto", Utrecht, Países Bajos.

Prince, E., Frader, R. \& Bosk, C. (1982). On hedging in physician-physician discourse. En J. di Prieto (Ed.), Linguistics and the professions (pp. 83-97). Londres: Ablex Publishing.

Pulido, M. (1989). El artículo de revisión. Medicina Clínica, 93(19), 413-414.

Réfega de Figueiredo-Silva, M. (2001). Teaching academic reading: Some initial findings from a session on hedging. Ponencias del Postgraduate Conference 2001. Department of Theoretical and Applied Linguistics, Universidad de Edinburgo, Edinburgo, Reino Unido.

Rosenblatt, L. (1985a). Language, literature and values. En S. Tchudi (Ed.), Language schooling and society (pp. 65-79). New York: Boynton/Cook.

Rosenblatt, L. (1985b). Writing and reading: The transactional theory. Reporte técnico $N^{0} 416$. New York: New York University.

Salager-Meyer, F. (1994). Hedges and textual communicative function in Medical English written discourse. English for Specific Purposes, 13(2), 149-170.

Salager-Meyer, F., Defives, G. \& Hamelynck, M. (1996). Epistemic modality in 19th and 20th century medical English written discourse: A principal component analysis. Interface. Journal of Applied Linguistics, 10, 163-199.

Salager-Meyer, F. \& Defives, G. (1998). From the gentleman's courtesy to the scientist's caution: A diachronic study of hedges in academic writing (1810-1995). En I. Fortanet, S. Posteguillo, J. Palmer \& J. Coll (Eds.), Genre studies in English for academic purposes (pp. 133-173). Valencia: Universitat Jaume I.

Samuels, J., \& Laberge, D. (1985). Toward a theory of automatic information processing in reading. 
En H. Singer \& R. Ruddell (Eds.), Theoretical models and processes of reading (pp. 548-579). Newark, DE: International Reading Association.

Smith, F. (1990). Para darle sentido a la lectura. Madrid: Visor.

Smith, F. (1997). Between hope and havoc. Postmouth, NH: Heinemann.

Smith, F. (1999). El futuro de la lectura y la escritura y las nuevas tecnologías. Conferencia presentada en el IV Congreso Colombiano y V Congreso Latinoamericano de Lectura y Escritura, Bogotá, Colombia.

Swales, J. (1990). Genre analysis: English in academic research settings. Glasgow: Cambridge University Press.

Varttala, T. (2001). Hedging in scientifically oriented discourse. Exploring variation according to discipline and intended audience [en línea]. Disponible en: http://acta.uta.fi/pdf/951-445195-3.pdf

Vold, E. (2006). Epistemic modality markers in research articles: A cross-linguistic and cross-disciplinary study. International Journal of Applied Linguistics, 16(1), 61-87.

Webber, P. (1994). The function of questions in different medical journals. English for Specific Purposes, 13(3), 257-268.

\section{NOTAS}

1 Este estudio forma parte del proyecto de Tesis de Doctorado "Estudio retórico discursivo de la atenuación en el discurso escrito de Odontología: Artículos de investigación, casos clínicos y artículos de revisión publicados en revistas hispanas entre 1999 y 2005", dirigido por Daniel Cassany. Está inserta en el proyecto de investigación: Descripción de algunas prácticas letradas recientes. Análisis lingüístico y propuesta didáctica (HUM2007-62118/FILO), de la Universitat Pompeu Fabra, Barcelona, España http://www.upf.edu/dtf/recerca/grups/grael/LC/index.htm. Para el desarrollo del proyecto, recibimos financiamiento del Consejo de Desarrollo Científico, Humanístico y Tecnológico de la Universidad de Los Andes, Mérida, Venezuela, código 0-177-06-06-A.

2 Por razones de espacio, hemos hecho referencia solo a algunas de las preguntas de los cuestionarios.

3 En la presentación de los ejemplos, respetamos la ortografía y la puntuación originales empleadas en el AR y en las respuestas de los estudiantes. Los subrayados son nuestros. 


\section{ANEXOS}

Vínculos de la documentación utilizada:

Artículo de revisión: Guilarte, C. Perrone, M. (2004). Microorganismos de la placa dental relacionados con la etiología de la periodontitis. Acta Odontológica Venezolana, 42 (3). http: / /www. actaodontologica.com $/ 42 \% 5 \mathrm{~F} 3 \% 5 \mathrm{~F} 2004 /$ microorganismos_placa_dental_etiologia_periodontitis. asp, en http: / / www.scielo.org.ve/scielo.php?pid=S0001-63652004000300012\&script=sci_arttext y en: http://webdelprofesor.ula.ve/odontologia/oscarula > Introducción a la Investigación > Microorganismos de la placa dental relacionados con la etiología de la periodontitis.

Cuestionario primero: http://webdelprofesor.ula.ve/odontologia/oscarula > Introducción a la Investigación > Primer cuestionario del artículo "Microorganismos de la placa dental".

Cuestionario segundo: http://webdelprofesor.ula.ve/odontologia/oscarula > Introducción a la Investigación > Segundo cuestionario del artículo "Microorganismos de la placa dental". 